Thorax, 1978, 33, 761-763

\title{
Deep vein thrombosis after thoracotomy
}

\author{
F R JACKAMAN, B J PERRY, AND HAROLD SIDDONS
}

From the Departments of Surgery and Medical Physics, St George's Hospital, London SW1, UK

Jackaman, F R, Perry, B J, and Siddons, H (1978). Thorax, 33, 761-763. Deep vein thrombosis after thoracotomy. In a prospective study of 183 patients undergoing lateral thoracotomy the ${ }^{125}$ I fibrinogen uptake test and perioperative heparin prophylaxis for deep-vein thrombosis were investigated. There was an incidence of deep vein thrombosis of $51 \%$ in untreated control patients. The heparin prophylaxis effectively reduced the incidence of deep venous thrombosis to $28 \%(\mathrm{P}<0.005)$ without increasing postoperative blood loss. Unilateral thrombosis was found to be significantly more frequent in the leg opposite the side of the thoracotomy $(P<0.005)$. The ${ }^{125}$ I fibrinogen test is essential in assessing methods of prophylaxis but is not recommended as a routine.

The incidence and methods of prevention of deep vein thrombosis (DVT) in surgical patients have been studied increasingly since the introduction of the ${ }^{25}$ I-labelled fibrinogen uptake test (Flanc et al, 1968; Kakkar et al, 1969; Browse et al, 1971; Loudon, 1976). Published investigations have included patients undergoing many types of major and minor surgical procedures (Browse and Negus, 1970; Williams, 1971; Gordon-Smith et al, 1972; Kakkar et al, 1972; Nicolaides et al, 1972; Venous Thrombosis Clinical Study Group, 1975).

Although some series include a few thoracic surgical patients (Atkins and Hawkins, 1968; Gallus et $a l, 1973$ ) no other experience of this test in a large series has so far been presented.

Patients undergoing lateral thoracotomy form a compact group, which is particularly suitable for detailed study because of the uniformity of pre-, intra- and postoperative management. This paper reports the results of routine screening for DVT with and without a specific method of prophylaxis for such a group.

\section{Patients}

In a three year period all patients undergoing lateral thoracotomy for the conditions listed in table 1 have been routinely screened for DVT by the ${ }^{125}$ I fibrinogen test. Lateral thoracotomy was performed in most cases by one of us (HS). Blood loss at and after operation was measured.

In the first year of the study no specific prophylaxis against DVT was given; thereafter a lowdose heparin regimen was used in patients over 40 years of age. Heparin sulphate 5000 IU 12-
Table 1 Diagnoses of 183 patients undergoing lateral thoracotomy

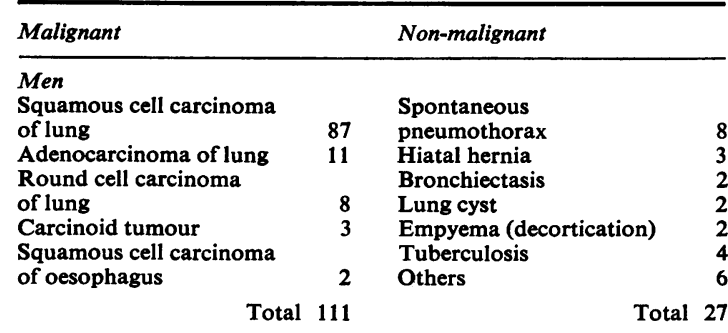

\section{Women}

Squamous cell carcinoma of lung

Adenocarcinoma of lung

Round cell carcinoma

of lung

Carcinoid tumour

Carcinoma of stomach

Fibrosarcoma

Spontaneous

pneumothorax 2

Hiatal hernia

Bronchiectasis

Lung cyst

Empyema (decortication)

Others

Total 30

Total 15

hourly was given subcutaneously for five days, the first dose being given one hour before operation. Routine pre- and postoperative nursing and physiotherapy were similar for all patients.

\section{${ }^{125}$ I fibrinogen test}

The intravenous injection of $1 \cdot 1 \mathrm{ml}(100 \mu \mathrm{Ci})^{125} \mathrm{I}-$ labelled fibrinogen (Radiochemical Centre, Amersham-Code IM 53P) was given on the day before the operation, the thyroid having been blocked by potassium iodide $120 \mathrm{mg}$, given by mouth 24 hours previously. The uptake of radioactivity was 
measured with a Pitman 235 Isotope Localisation Monitor using the detector and collimator normally supplied and with the collimator in its fully retracted position. A set of measurements consisted of readings at marked positions $5 \mathrm{~cm}$ apart on the medial aspect of each leg. They were expressed as a percentage of the activity measured by the initial reading of each set, which was taken over the heart. Measurements were normally made immediately before operation and then daily for seven consecutive days. If abnormally high counts were being detected, however, measurements were continued at less frequent intervals up to 14 days. A second ${ }^{125}$ I fibrinogen injection was never given.

The criterion for abnormal ${ }^{125} \mathbf{I}$ fibrinogen uptake was taken to be a rise of $20 \%$ at any one position compared with adjacent positions on at least two consecutive days.

\section{Results}

In 118 patients of the 183 studied the pattern of ${ }^{125} \mathrm{I}$ fibrinogen uptake was normal, and in 65 patients there was abnormally high uptake (table 2). Sixty-three patients had no heparin prophylaxis, and in 120 heparin was used as described.

Table 2 Effect of prophylactic heparin

\begin{tabular}{lclc}
\hline & Test normal & $\begin{array}{l}\text { Test abnormal } \\
(\text { high })\end{array}$ & Totals \\
\hline No heparin & 31 & 32 & 63 \\
Heparin & 87 & 33 & 120 \\
Totals & 118 & 65 & 183 \\
\hline
\end{tabular}

$x^{2}=8.8 \quad P<0.005$.

There was a significantly lower incidence of abnormal test results among those patients who had received heparin-33/120 (28\%) in comparison with $32 / 63(51 \%)$ for the non-heparinised controls (Chi-squared test with Yates's correction $8.8 \mathrm{P}<0.005)$. The same pattern of lower incidence was found in men and women and in patients with malignant and non-malignant disease. No patients in the study developed clinical evidence of pulmonary embolism.

SITE OF ABNORMAL FIBRINOGEN UPTAKE

Of the 65 patients with abnormally high uptakes, in 32 one leg only was affected, while in the remaining 33 both legs were affected. Of these 33 the bilateral uptake was symmetrically placed in 26. The criterion for symmetry was taken as an increased uptake of comparable duration in the same or immediately adjacent measurement posi- tion in both legs. The analysis of abnormal uptakes with respect to site was left leg only (14), right $\frac{}{\omega}$ leg only (18), bilateral asymmetrical (7), and bilateral symmetrical (26).

These data have been analysed with respect to कs the side of operation. The figures are given in $\overrightarrow{0}$ table 3 for the group of patients where there was $\overrightarrow{-}$ abnormal uptake in one leg only. For this selected $\vec{\omega}_{\sigma}$ group there was a higher incidence of abnormal uptake in the leg opposite the side of the thora- $x$ cotomy (Chi-squared test $8.0 \mathrm{P}<0.005$ ). If all abnormals are included, however, $\chi^{2}$ gives a value of $\sigma$ $2 \cdot 6(\mathrm{P}=0 \cdot 1)$.

Table 3 Analysis of site of abnormal scans with respect to side of operation (abnormal uptake in one leg only)

\begin{tabular}{|c|c|c|}
\hline \multirow[t]{2}{*}{ Side of operation } & \multicolumn{2}{|c|}{ Site of abnormal uptake } \\
\hline & $\begin{array}{l}\text { Same side as } \\
\text { operation }\end{array}$ & $\begin{array}{l}\text { Opposite side to } \\
\text { operation }\end{array}$ \\
\hline $\begin{array}{l}\text { Right } \\
\text { Left }\end{array}$ & $\begin{array}{l}4 \\
4\end{array}$ & $\begin{array}{l}10 \\
14\end{array}$ \\
\hline Totals & 8 & 24 \\
\hline
\end{tabular}

$\chi^{2}=8.0 \mathrm{P}<0.005$.

BLOOD LOSS AT OPERATION

All classes of operation had a wide range of blood loss values. The spread was such that average values have little meaning, but there was no evidence to suggest that greater blood loss occurred when heparin was used.

\section{Discussion}

The value of the low dose heparin in preventing postoperative DVT has been well proved in many series of major and minor general surgical operations (Williams et al, 1971; Gordon-Smith et al, 1972; Kakkar et al, 1972; Nicolaides et al, 1972; Gallus et al, 1973). In these series the incidence of abnormal ${ }^{125}$ I uptake tests in non-heparinised con- No trols varied between $16 \%$ and $42 \%$. Our results show an incidence of thrombosis of $51 \%$ in control patients. Although with our heparin regimen we have shown a reduction in this incidence at a level of significance that is similar to most other studies $(\mathrm{P}<0.005)$, our residual thrombosis rate of $28 \%$ after prophylaxis remains high. A large proportion of patients with malignancy $(77 \%)$, and the extent of the surgical procedure in this series, may have contributed to this high incidence. It should be noted, however, that unlike most of the trials of heparin prophylaxis reported, this was a sequential rather than a prospective randomly 
allocated study, and this has resulted in $83 \%$ of cases with cancer in the non-treated group as distinct from $74 \%$ of cases in the treated group. The high incidence of DVT in a series that is a typical case-mix of thoracic surgical practice, emphasises the need for effective prophylaxis.

\section{LIMB TRAUMA DURING SURGERY}

Our results show a definite correlation between the side of operation and the opposite leg in those patients with high uptake in one leg (24 out of 32 patients), although this group is only half of all abnormal cases.

In most patients the increased uptake was detected in the first few days after operation, suggesting that the thrombotic process starts during the operation. With the patient in position for lateral thoracotomy there may be direct trauma to the calf veins and impaired venous blood flow in the legs during the operation. The leg lying on the table may be more affected than the other leg.

In addition, accidental bruising of patients due to handling while under anaesthesia can occur, and we have seen symmetrical bruising of both lower calves. The bruising may be slight in most cases and at the surface of the limb. The poor depth response of the detector to ${ }^{125} \mathrm{I}$, especially when it is used close to the skin, will give an unwanted significance to such near surface concentrations of radioactivity, confusing them with truly deep thrombi.

A significant reduction in the incidence of DVT after operation has been achieved by intermittent pneumatic calf compression (Hills et al, 1972) and these pneumatic leggings may prevent some effects of trauma as well as venous pooling. Perhaps a combination of this physical method of prophylaxis and perioperative subcutaneous heparin would be appropriate for patients undergoing lateral thoracotomy.

Our thanks are due to physics isotope radiographers Miss G Cochrane and Mrs M Morley and to the superintendent radiographer in the radiotherapy department, Miss A Clewes, for the measurements of patients.

\section{References}

Atkins, P, and Hawkins, L A (1968). The diagnosis of deep vein thrombosis in the leg using ${ }^{125} \mathrm{I}$ fibrinogen. British Journal of Surgery, 55, 825-830.
Browse, N L, and Negus, D (1970). Prevention of postoperative leg vein thrombosis by electrical muscle stimulation. An evaluation with ${ }^{125} \mathrm{I}$ labelled fibrinogen. British Medical Journal, 3, 615-618.

Browse, N L, Clapham, W F, Croft, D N, Jones, D J, Thomas, M L, and Williams, J O (1971). Diagnosis of deep vein thrombosis with ${ }^{125}$ I fibrinogen uptake test. British Medical Journal, 4, 325-328.

Flanc, C, Kakkar, V V, and Clarke, M B (1968). The detection of venous thrombosis of the legs using ${ }^{125} \mathrm{I}$ labelled fibrinogen. British Journal of Surgery, 55, 742-747.

Gallus, A S, Hirsh, J, Tuttle, R J, Trebilcock, R, O'Brien, S E, Carroll, J J, Minden, J H, and Hudecki, S M (1973). Small subcutaneous doses of heparin in prevention of venous thrombosis. New England Journal of Medicine, 288, 545-551.

Gordon-Smith, I C, Grundy, D J, Le Quesne, L P, Newcombe, J F, and Bramble, F J (1972). Controlled trial of two regimens of subcutaneous heparin in prevention of post-operative deep vein thrombosis. Lancet, 1, 1133-1135.

Hills, N H, Pflug, J J , Jeyasingh, K, Boardman, L, and Calnan, J S (1972). Prevention of deep-vein thrombosis by intermittent pneumatic compression of calf. British Medical Journal, 1, 131-135.

Kakkar, V V, Howe, C T, Flanc, C, and Clarke M B (1969). Natural history of post-operative deep-vein thrombosis. Lancet, 2, 230-232.

Kakkar, V V, Corrigan, T, Spindler, J, Fossard, D P, Flute, $\mathbf{P}$ T, Crellin, $\mathbf{R}$ Q, Wessler, $\mathrm{S}$, and Yin, E T (1972). Efficiency of low doses of heparin in prevention of deep-vein thrombosis after major surgery. Lancet, 2, 101-106.

Loudon, J R (1976). ${ }^{125}$ I fibrinogen uptake test. British Medical Journal, 2, 793.

Nicolaides, A N, Dupont, P A, Desai, S, Lewis, J D, Douglas, J N, Dodsworth, H, Fourides, G, Luck, R J, and Jamieson, C W (1972). Small doses of subcutaneous sodium heparin in preventing deep venous thrombosis after major surgery. Lancet, 2, 890-893.

Williams, H T (1971). Prevention of post-operative deep-vein thrombosis with perioperative subcutaneous heparin. Lancet, 2, 950-952.

Venous Thrombosis Clinical Study Group (1975). Small doses of subcutaneous sodium heparin in the prevention of deep-vein thrombosis after elective hip operations. British Journal of Surgery, 62, 348350 .

Requests for reprints to: Mr F R Jackaman, Department of Surgery, South Nottingham District General Hospital, Nottingham NG1 6HA. 